Int. J. Electrochem. Sci., 15 (2020) 1930 - 1941

\title{
Ultrasensitive Electrochemical Approach for Gemifloxacin Mesylate Monitoring and Quantification by Different Voltammetric Methods
}

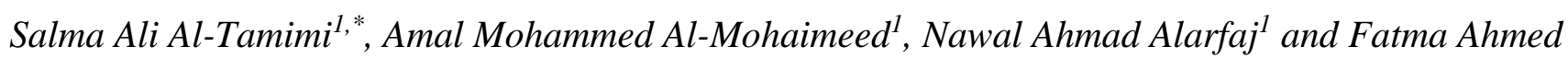 \\ $A l y^{2}$ \\ ${ }^{1}$ Department of Chemistry, College of Science, King Saud University, P. O. Box 22452, Riyadh \\ 11495, Saudi Arabia \\ ${ }^{2}$ Department of Pharmaceutical Analytical Chemistry, Faculty of Pharmacy, Mansoura University, \\ Mansoura 35516, Egypt \\ *E-mail: satamimi@ksu.edu.sa
}

doi: $10.20964 / 2020.03 .51$

Received: 3 November 2019 / Accepted: 12 January 2020 / Published: 10 February 2020

The voltammetric behavior of the Gemifloxacin mesylate (GFX) on hanging mercury dropping electrode (HMDE) was studied using three different voltammetry modes. A well-defined cathodic peak was obtained in acetate buffer $\mathrm{pH}$ 5.0. An irreversible and diffusion controlled peak was characterized. The relationships between the current and the concentration of the investigated drug were plotted and displayed linearity over the concentration ranges of $0.01-0.19 \mu \mathrm{g} \mathrm{mL}^{-1}, 0.006-0.13 \mu \mathrm{g} \mathrm{mL}^{-1}$ and $0.008-0.27 \mu \mathrm{g} \mathrm{mL}^{-1}$ with minimum detection limits of $1.49,2.06$ and $2.34 \mathrm{ng} \mathrm{mL}^{-1}$ using DPV, SWV and CV modes, respectively. The suggested electrochemical approaches were successfully used to determine GFX in commercial products such as tablets, and the outcome data were analyzed statistically and their agreement with those from previously conducted spectrophotometric method was evaluated. The simplicity and potential sensitivity of the suggested approaches allows the assay of GFX in the bio-media. The reaction pathway was postulated.

Keywords: Gemifloxacin mesylate; Electrochemical study; Three voltammetric modes; biological applications

\section{$\underline{\text { FULL TEXT }}$}

(C) 2020 The Authors. Published by ESG (www.electrochemsci.org). This article is an open access article distributed under the terms and conditions of the Creative Commons Attribution license (http://creativecommons.org/licenses/by/4.0/). 